\title{
Effective Treatment of Inflammatory Linear Verrucous Epidermal Nevus with Pulsed 5-Fluoruracil Therapy
}

\author{
Mohammed Al Abadie ${ }^{1^{*}}$, Shagufta Parveen ${ }^{1}$ and Mohammed Al-Rubaye ${ }^{2}$ \\ ${ }^{1}$ Department of Dermatology, Royal Wolverhampton NHS Trust/University Of Birmingham, Wolverhampton, UK \\ ${ }^{2}$ Clinical Fellow General Internal Medicine, Royal Wolverhampton NHS Trust, UK
}

"Corresponding author: Mohammed Al Abadie, Department of Dermatology, Royal Wolverhampton NHS Trust/University of Birmingham, Wolverhampton, UK, E-mail: mohammed.abadie@nhs.net

Received date: November 20, 2018; Accepted date: December 21, 2018; Published date: December 28, 2018

Copyright: $\odot 2018$ Al Abadie M, et al. This is an open-access article distributed under the terms of the Creative Commons Attribution License, which permits unrestricted use, distribution, and reproduction in any medium, provided the original author and source are credited.

\begin{abstract}
Fundaments: Inflammatory Linear Verrucous Epidermal Nevus (ILVEN) is an uncommon condition, which presents early in childhood as erythematous pruritic papules or plaques in an asymmetrical pattern. The lesions tend to appear on the left side of the body and are extremely resistant to treatment, which make this disease a psychological and social burden on the children and parents alike.
\end{abstract}

Keywords: Inflammatory linear epidermal nevus; Papules; Lesions; Epidermis; skin

\section{Introduction}

Inflammatory Linear Epidermal Naevus (ILVEN) is a skin condition, which presents initially as pink or red papules, which later converge into larger linear plaques most commonly on the distal arms and legs [1]. They can also involve the trunk and back area and may follow Blaschko's lines [2]. The lesions are usually pruritic and may appear disfiguring especially in more exposed areas [2]. This condition affects children of all age groups and tends to present by the age of 6 months [1,3]. Treatment is usually difficult as most lesions are extremely resistant to many treatment modalities and regimens $[4,5]$. In this paper we will discuss the different treatment options that have been tried in previous patients and the success achieved by using different combinations.

\section{Case Report}

Three-year-old male presented with a history of pruritic lesions on the left side of his forehead, left forearm and buttocks for the last 1.5 years (Figure 1). New lesions are continuing to appear with none of the initial lesions showing improvement. On examination the lesions are erythematous, raised and linear in their distribution. A $4 \mathrm{~mm}$ punch biopsy was performed on the left forearm, which showed thickened parakeratin overlying the epidermis. The epidermal changes include mild papillomatosis and regular acanthosis. The dermis and subcutis were unremarkable.

The boy's lesions were resistant to treatment with emollients and topical steroids (including betnovate and dermovate) and single treatment with $5 \%$ Fluorouracil cream for 2 weeks but pulsed 5\% Fluorouracil cream used daily for 3 weeks followed by a 1 month gap and a further $2^{\text {nd }}$ pulse for 3 weeks proved to be successful and showed an improvement of $80 \%-90 \%$ of the lesions. The lesions on the left side of the forehead were particularly resistant to initial treatment with potent topical steroids and single pulse therapy of $5 \%$ Fluorouracil however they responded extremely well as shown in the picture below (Figure 2).

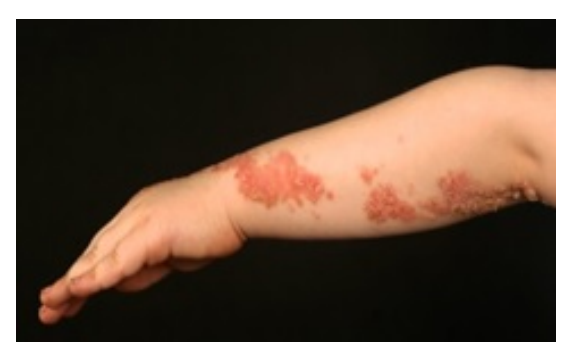

Figure 1: Classical presentation of ILVEN with erythematous, raised hyperkeratotic lesions usually affecting the left side of the body. Lesions may be linear and are almost always pruritic.

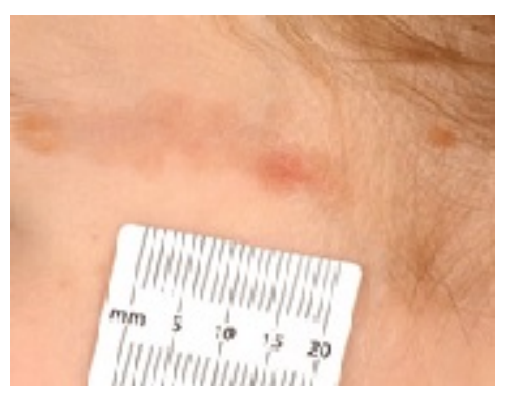

Figure 2: Excellent response of ILVEN to pulsed 5-FU therapy. This lesion on the forehead was especially resistant to combined treatment with potent topical steroids and single treatment 5-FU however it responded really well with only minor erythema and hyperkeratosis remaining. 


\section{Epidemiology/Genetics}

Epidermal nevi occur in approximately 1-3/100,000 live births [6]. ILVEN makes up less than $10 \%$ of this figure which makes this condition quiet rare with dermatologists often only seeing a few throughout their career [7]. Most cases of ILVEN are sporadic but some familial cases have been described in the past. An autosomal dominant mutation may cause the development of ILVEN but may also cause lethal results if all cell lines are affected [8]. Mosaicism in turn prevents the lethal effects if all cell lines are affected resulting in ILVEN [8].

\section{Discussion}

First of all we will discuss the clinical features of the condition. ILVEN presents as an intensely pruritic, initially papular condition that classically follows Blaschko's lines [1,2]. The lesions progress from papular lesions to linear hyperkeratotic plaques and usually involve the left side of the body $[1,4,9]$. The typical patient is a young child who had presented with an asymmetrical itchy eczematous or psoriasiform rash which continually spread despite treatment [9]. ILVEN may present as a symmetrical or bilateral rash however this is uncommon. Altman and Mehregan set out 6 points for making a diagnosis of ILVEN [1,3]:

- Early age of onset (75\% before the age of 5 years and $50 \%$ before the age of 6 months)

- Female : male ratio of 4:1

- Pruritus

- Left sided predominance of lesions

- Psoriasis like aspect

- Resistance to treatment

\section{Management}

The management of ILVEN has always caused significant distress to patients and doctors alike. Despite many attempts at different treatment options and regimens ILVEN is very resistant and explaining to patients parents that a quick resolution might not be possible is important to keep patients hopes under control. Steroids have been used in the management of ILVEN for a long period of time and provide good symptomatic relief [4]. They can be administered topically under occlusion or as an intralesional steroid injection [4]. One study also demonstrated benefit in treating ILVEN with $0.1 \%$ tretinoin combined with 5\% 5-fluorouracil in a young patient [10]. Another study showed good results with the treatment of limb ILVEN with tacrolimus $0.1 \%$ ointment combined with fluocinonide [11]. Dithranol [12] and $\mathrm{CO}_{2}$ resurfacing laser [13] have been used in the past with variable success. Pruritus has successfully been managed with topical pimecrolimus cream [14]. Many different treatment options have been tried in the past such as cryotherapy, laser ablation and chemical peel but these have resulted in a high risk of recurrence [15]. Full thickness skin surgery has been used on selected patients who are resistant to all medical treatment options [16]. This option removes the lesions completely and is associated with a low chance of recurrence however is not practical for many patients and is not considered in most unless clinically indicated. Complete spontaneous resolution has been described in the past but is an infrequent occurrence and most patients undergo many treatment changes before any resolution [2] (Figure 2).

\section{Conclusion}

ILVEN is an uncommon condition affecting children and most commonly presents as an asymmetrical pruritic papular rash affecting the left side of the body $[1,3]$. Linear hyperkeratotic plaques usually follow and the condition is significantly resistant to many available treatments licensed for managing the disease $[1,4,5]$. Many different treatment approaches have been used in the past with some demonstrating success in managing symptoms as well as the condition itself. The condition however remains quite difficult to manage although a small minority has had spontaneous resolution [2].

\section{References}

1. Altman J, Mehregan AH (1971) Inflammatory linear verrucous epidermal nevus. Arch of dermatol 104: 385-389.

2. Cerio R, Wilson Jones E, Eady J (1992) ILVEN responding to occlusive potent topical steroid therapy. Clin Exp Dermatol 17: 279-281.

3. Morag C, Metzker (1985) A inflammatory linear verrucous epidermal naevus: Report of seven new cases and review of literature. Pediatr Dermatol 3: 15-18.

4. Hodge SJ, Barr JM, Owen LG (1978) Inflammatory linear verrucous epidermal nevus. Arch Dermatol 114: 436-443

5. Cokerell CJ, Larson F (2007) Benign epidermal tumors and proliferations. In: Bolognia J, Jorizzo J, Rapini R (eds.) Dermatology, (2nd edn), New York: Elsevier. 200: 1671-1673

6. Brandling-Bennet HA, Morel KD (2010) Epidermal nevi. Pediat Clin North AM 57: 1177.

7. Silver SG, Ho VCY (2003) Benign epithelial tumors. In: Freedberg IM, Eisen AZ, Wolff K (eds.) Fitzpatrick's dermatology in general medicine 6 : 767-785

8. Happle R (1987) Lethal genes surviving by mosaicism: A possible explanation for sporadic birth defects involving the skin. J Am Acad Dermatol 16: 899-906.

9. Gon AS, Minelli L, Franzon PG (2010) A case for diagnosis. Ann Bras Dermatol 85: 729-731.

10. Kim JJ, Chang MW, Shwayder T (2000) Topical tretinoin and 5Fluorouracil in treatment of linear verrucous epidermal nevus. J Am Acad Dermatol 43: 129-132.

11. Mutasim D (2006) Successful treatment of inflammatory linear verrucous epidermal nevus with tacrolimus and fluocinonide. J Cutan Med Surg 10: 45-47.

12. De Mare S, Van Der Kerhof PCM, Happle R (1989) Dithranol in the treatment of inflammatory linear verrucous epidermal nevus. Acta Dermatol Venereal 69: 77-80.

13. Ulkur E, Celikoz B, Yuksel F (2004) Carbon dioxide laser therapy for an inflammatory linear verrcous epiderma nevus. Aesthetic Plast Surg 28: 428-430.

14. Gratch NS, liang D, Scott R, Lao P (2004) Pruritus of ILVEN relieved by topical pimecrolimus cream. J Am Acad Dermatol 50: 48.

15. Burks WJ (1979) Demabrasaion and chemical peeling in the treatment of certain cosmetic defects and diseases of the skin. Springfield, Ill : Thomas, US.

16. Behera B, Devi B, Nayak BB, Sahu B, Singh B, et al. (2013) Giant inflammatory linear verrucous epidermal nevus successfully treated with full thickness excision and skin grafting. Indian J. Dermatol 58: 461-463. 